\title{
TEKNOSIAR
}

WADAH KOMUNIKASI ILMIAH

homepage URL : http://uniflor.ac.id/e-journal/index.php/TEKNOSIAR

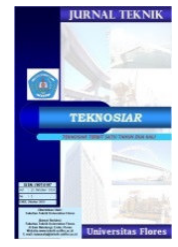

\section{Analisis Kinerja Simpang Patung Pahlawan Marilonga Ende}

\author{
De Noval La Tuga ${ }^{1}$, Thomas Aquino A. Sydin ${ }^{2}$ \\ ${ }^{1,2}$ Program Studi Teknik Sipil, Fakultas Teknik, Universitas Flores, Ende \\ ${ }^{*}$ Correspondence email : oniuqasamoth@gmail.com
}

\begin{abstract}
The Marilonga Ende Statue of Heroes intersection is one of the most crowded intersections because it has direct access to the Wolowona market, and is also traversed by the main and continuous traffic movement via the trans Flores road.

This study aims to determine how big the current performance conditions of the intersection. The data required is in the form of traffic volume and environmental conditions. The indicators for evaluating the performance of intersections are based on the guidelines of the Indonesian Road Capacity Manual (Ministry of Public Works, 1997).

The results showed that the performance of the Marilonga Ende Statue of Heroes intersection in non-ideal boundary conditions, the value of the degree of saturation (DS) was 0.75, the delay was $13.4866 \mathrm{sec} / \mathrm{pcu}$, and the queue probability $(Q P)$ was $22 \%$ - 45\%. After controlling efforts in the form of regulating vehicle movement and prohibiting the use of roadside activities that have an impact on side barriers to be low. The performance of the intersection has decreased, with a degree of saturation (DS) of 0.31, a delay value of $8.1031 \mathrm{sec} / \mathrm{pcu}$, and a queue probability $(Q P)$ of $5 \%$ - 14\%. So that efforts to maintain the performance of the intersection through the installation of traffic signs in the form of being prohibited from going against the direction, prohibited from parking, and prohibited from stopping are some of the control methods that can be used to overcome the problem of traffic movement at the Marilonga Ende Statue of Heroes intersection.
\end{abstract}

Keywords: capacity, traffic flow, degree of saturation, delay, queue opportunity, Leve of service

\begin{abstract}
ABSTRAK
Simpang Patung Pahlawan Marilonga Ende merupakan salah satu simpang yang cukup ramai karena memiliki akses langsung ke pasar Wolowona, dan juga dilalui peregerakan lalu lintas utama dan menerus yang melalui jalan trans Flores.

Penelitian ini bertujuan untuk mengetahui seberapa besar kondisi kinerja simpang saat ini. Data yang diperlukan berupa volume lalu lintas dan kondisi lingkungan. Indikator penilaian kinerja simpang berdasarkan pedoman Manual Kapasitas Jalan Indonesia (Departemen Pekerjaan Umum, 1997).

Hasil penelitian menyatakan bahwa kinerja simpang Patung Pahlawan Marilonga Ende dalam kondisi batas yang tidak ideal, nilai derajat kejenuhan (DS) sebesar 0,75, tundaan 13,4866 det/smp, dan peluang antrian (QP) $22 \%-45 \%$. Setelah dilakukan upaya pengendalian berupa pengaturan pergerakan kendaraan dan pelarangan penggunaan aktivitas sisi jalan yang berdampak pada hambatan samping menjadi rendah. Kinerja simpang mengalami penurunan, dengan nilai derajat kejenuhan (DS) sebesar 0,31, nilai tundaan 8,1031 det/smp, dan peluang antrian (QP) $5 \%$ - 14\%. Sehingga upaya mempertahankan kinerja simpang melalui pemasangan rambu lalu lintas berupa dilarang melawan arah, dilarang parkir, dan dilarang berhenti merupakan beberapa cara pengendalian yang bisa digunakan untuk mengatasi permasalahan pergerakan lalu lintas yang ada pada simpang Patung Pahlawan Marilonga Ende.
\end{abstract}

Kata kunci : kapasitas, arus lalu lintas, derajat kejenuhan, tundaan, peluang antrian, tingkat pelayanan

TEKNOSIAR Volume 14, No.01, April 2020

p-ISSN 1907-5197 (versi cetak) e-ISSN 2721-2270 (versi online) 


\section{PENDAHULUAN}

Keberadaan sarana dan prasarana transportasi di Provinsi Nusa Tenggara Timur, khususnya di Kabupaten Ende merupakan faktor penting yang akan mempengaruhi perkembangan wilayah, serta menunjang aktivitas sosial, politik, ekonomi, budaya dan lain-lain. Peranan transportasi sangat besar dalam kehidupan masyarakat karena tujuan transportasi ialah memberikan kemudahan dalam segala kegiatan masyarakat. Kemudahan ini diartikan sebagai mudahnya lokasi tujuan dicapai, mudahnya pergerakan penduduk, dan mudahnya faktor-faktor produksi didapat.

Kota Ende merupakan kota yang sedang gencar melakukan pembangunan disegala bidang, terutama dibidang transportasi, tentu menuntut ketersediaan sarana dan prasarana transportasi yang memadai, melihat kondisi tersebut dan memperhatikan tingkat perkembangan kota serta pertumbuhan lalu lintas, diperlukan perencanaan dan pengendalian arus lalu lintas sehingga diharapkan mampu melayani arus lalu lintas pada jalan raya. Jalan raya merupakan salah satu sub komponen prasarana sistem transportasi yang paling dominan dan digunakan setiap hari oleh masyarakat yang melakukan perjalanan.

Pertambahan jumlah transportasi yang tidak diimbangi dengan perkembangan prasarana akan menimbulkan konflik pada jalan raya, khususnya simpang atau bundaran. Simpang adalah suatu daerah pertemuan dari jaringan jalan raya, dan juga tempat bertemunya kendaraan dari berbagai arah dan merubah arah, termasuk di dalamnya fasilitas-fasilitas yang diperlukan untuk pergerakan lalu lintas. Mengingat fungsi simpang yaitu mengalirkan dan mendistibusikan kendaraan, maka diharapkan dapat mengurangi konflik yang terjadi di persimpangan, hal ini dapat diatasi dengan berbagai cara peningkatan prasarana lalu lintas dan manajemen lalu lintas.

Simpang Patung Pahlawan Marilonga Ende ialah simpang empat tak bersinyal, dengan pulau jalan di tengah simpang, yang bertujuan sebagai kanalisasi arus lalu lintas. Simpang ini merupakan jalan arteri yang pada jam-jam sibuk terjadi tundaan kendaraan, hal ini disebabkan karena daerah sekitar persimpangan tersebut merupakan area perdagangan, serta jalur menuju pusat kota sehingga arus lalu lintasnya cukup padat. Terdapat pertemuan empat ruas jalan pada simpang ini, yaitu Jalan Sultan Hasanudin (arah utara), Jalan Gatot Soebroto (arah selatan), Jalan Ndona (arah timur), dan Jalan Sam Ratulangi (arah barat). Pergerakan kendaraan di persimpangan merupakan penyebab utama terjadinya konflik lalu lintas, seperti pergerakan kendaraan dari Jalan Gatot Soebroto yang bergerak membelok ke kiri atau ke kanan maupun bergerak lurus, akan menyebabkan terjadinya konflik dengan kendaraan dari arah Jalan Sam Ratulangi, Jalan Sultan Hasanudin, dan Jalan Ndona. Lengan simpang arah Utara, yaitu area jalan Sultan Hasanudin merupakan tempat perniagaan (Pasar Wolowona), yang pada hari-hari tertentu khususnya hari pasar (Hari Jumad), hampir seluruh badan jalan digunakan untuk aktivitas jual beli, sehingga kerap kali menimbulkan tundaan yang cukup panjang dan lama hingga ke area persimpangan. Tundaan yang terjadi pada pergerakan kendaraan berakibat bertambahnya biaya operasional dan waktu tempuh kendaraan, ditambah lagi kendaraan yang parkir tidak pada tempatnya yakni di area persimpangan, seperti angkutan kota dan ojek yang menungggu penumpang, menyebabkan pergerakan arus lalu lintas di persimpangan terganggu dan terhambat. Kondisi simpang Patung Pahlawan Marilonga Ende saat ini sudah ada pelebaran lajur jalan, namun karena belum dilakukan manajemen lalu lintas yang tepat, sehingga pergerakan kendaraan yang melewati persimpangan menjadi tidak teratur. Sehingga diperlukan upaya pengaturan pergerakan lalu lintas pada simpang Patung Pahlawan Marilonga Ende sebagai bagian pengendalian lalu lintas yang menjamin pergerakan pengguna jalan menjadi lebih nyaman dan teratur.

Tujuan yang akan diperoleh dalam penelitian ini yakni mengetahui kinerja simpang Patung Pahlawan Marilonga Ende serta bagaimana upaya mengatur pergerakan lalu lintas melalui skenario pengendalian lalu lintas dalam mempertahankan kinerja simpang pada sesuai ketentuan MKJI, 1997. 


\section{METODE}

Data-data utama yang diperlukan dalam penelitian ini meliputi data volume lalu lintas, data inventori geometrik jalan dan tipe hambatan samping. Metode pengumpulan data yang dipakai yakni melalui observasi dengan melakukan pengamatan dan pengukuran secara langsung di lapangan atau di lokasi penelitian.

Survei volume lalu lintas dilakukan selama 3 hari yakni Senin, Rabu, dan Jumad melalui tiga periode waktu pagi, siang dan sore. Waktu penelitian untuk peride pagi dilakukan sejak pukul $06.00-09.00$ Wita, untuk periode siang hari, dilaksanakan pada pukul $11.00-14.00$ WITA, dan periode waktu sore hari dilaksanakan pada pukul $16.00-19.00$ WITA. Volume lalu lintas dicatat setiap 15 menit agar diperoleh data yang lebih akurat. Penentuan volume jam puncak dipilih dari hasil jumlah volume lalu lintas tertinggi yang terdapat pada setiap periode watu. Setelah diperoleh volume jam puncak, maka selanjutnya dilakukan perhitungan analisa kinerja simpang beserta analisa pengaturan pergerakan lalu lintas khususnya pergerakan yang berlawanan dengan arah pergerakan dalam rangka upaya mempertahankan kinerja simpang sesuai pedoman MKJI, 1997.

\section{HASIL DAN PEMBAHASAN}

\section{Kondisi Geometrik simpang}

Kondisi geometrik simpang Marilonga dapat dijelaskan pada gambar 1.1 berikut ini :

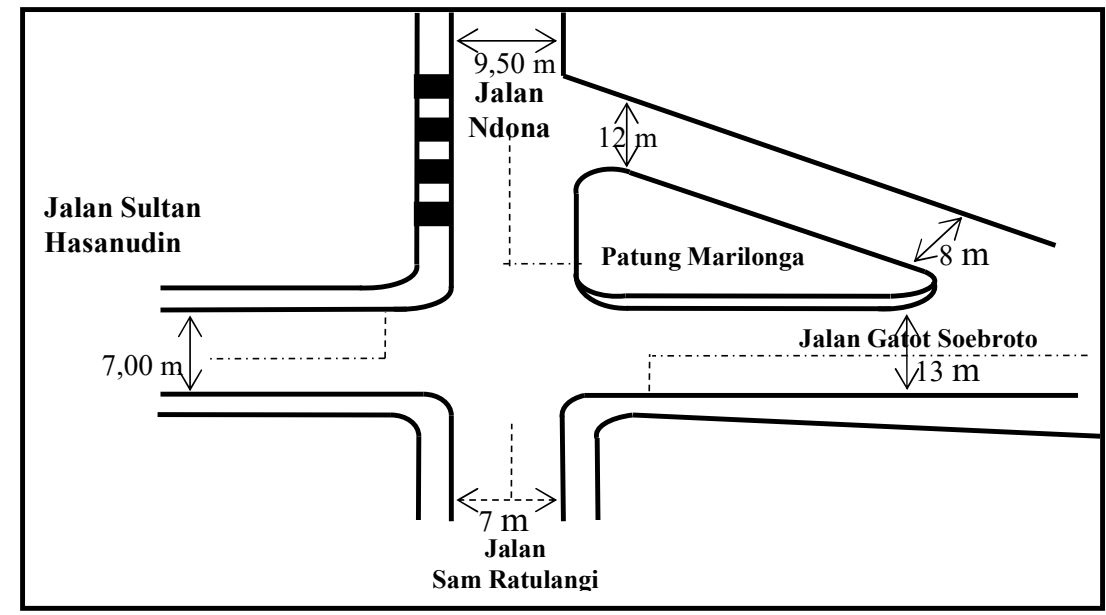

Gambar 1. Kondisi geometrik simpang

Sumber : Hasil penelitian, 2018

\section{Tipe lingkungan jalan}

Lokasi simpang berada pada lokasi perniagaan, usaha dagang, pasar sehingga tipe lingkungan tergolong dalam kategori komersial.

\section{Data Volume Lalu Lintas}

Dari volume lalu lintas pada jam puncak terjadi pada hari Jumad 13 April 2018 pukul $07.00-08.00$ WITA sebesar 2338,00 smp/jam. Namun karena kondisi tersebut merupakan kondisi tidak normal di mana adanya pasar mingguan yang hanya berlangsung beberapa jam saja, dan juga kendaraan yang melintaspun tidak teratur, maka data volume yang menjadi acuan dalam melakukan analisis, adalah data pada hari dengan kondisi normal, yaitu hari Senin 9 April 2018 pukul $07.00-08.00$ WITA yaitu 1.900,10 smp/jam. 
Tabel 1 Volume jam puncak

\begin{tabular}{|c|c|c|c|c|c|}
\hline \multirow{2}{*}{ No } & \multirow{2}{*}{$\begin{array}{c}\text { Periode waktu } \\
\text { (WITA) }\end{array}$} & \multicolumn{3}{|c|}{ Jumlah volume simpang (smp/jam) } & \multirow{2}{*}{ Ket } \\
\cline { 3 - 5 } & & Senin & Rabu & Jumad & \\
\hline 1 & $06.00-07.00$ & 1480,20 & 1351,10 & 1719,80 & \\
\hline 2 & $07.00-08.00$ & 1900,10 & 1705,30 & 2338,00 & \multirow{2}{*}{ PAGI } \\
\hline 3 & $08.00-09.00$ & 1287,70 & 1164,30 & 1682,10 & \\
\hline 4 & $11.00-12.00$ & 1384,50 & 1335,30 & 1861,50 & \multirow{2}{*}{ SIANG } \\
\hline 5 & $12.00-13.00$ & 1504,00 & 1251,00 & 1914,00 & \\
\hline 6 & $13.00-14.00$ & 1214,80 & 1035,40 & 1528,30 & \\
\hline 7 & $16.00-17.00$ & 1348,70 & 1139,10 & 1626,50 & \multirow{2}{*}{ SORE } \\
\hline 8 & $17.00-18.00$ & 1299,00 & 1147,90 & 1763,40 & \\
\hline 9 & $18.00-19.00$ & 901,70 & 799,00 & 1250,20 & \\
\hline
\end{tabular}

\section{Analisis Kinerja Simpang}

Analisa kinerja simpang pada jam puncak sebagai berikut :

1. Komposisi arus lalu lintas meliputi :

Volume kendaran ringan $\left(\mathrm{Q}_{\mathrm{LV}}\right) \quad=376,0 \mathrm{smp} / \mathrm{jam}$

Volume kendaraan berat $\left(\mathrm{Q}_{\mathrm{HV}}\right) \quad=36,4 \mathrm{smp} / \mathrm{jam}$

Volume sepeda motor ( $\left.\mathrm{Q}_{\mathrm{MC}}\right) \quad=1008 \mathrm{smp} / \mathrm{jam}$

Volume total kendaraan (Q

Volume kendaraan tak bermotor ( $\left.\mathrm{Q}_{\mathrm{UM}}\right) \quad=0 \mathrm{smp} / \mathrm{jam}$

Volume total kend. pada jalan minor ( $\left.\mathrm{Q}_{\mathrm{MI}}\right) \quad=573,6 \mathrm{smp} / \mathrm{jam}$

Volume total kend. pada jalan utama $\left(\mathrm{Q}_{\mathrm{MA}}\right) \quad=847 \mathrm{smp} / \mathrm{jam}$

Volume kend. belok kiri ( $\mathrm{Q}_{\mathrm{LT}}$ jln utama + jln minor $) \quad=440 \mathrm{smp} / \mathrm{jam}$

Volume kend. belok kanan $\left(\mathrm{Q}_{\mathrm{RT}} \mathrm{jln}\right.$ utama + jln minor $)=300 \mathrm{smp} / \mathrm{jam}$

2. Rasio berbelok

Rasio berbelok di bagi menjadi dua, yaitu :

Rasio berbelok kiri :

$$
\begin{aligned}
P_{L T} & =\frac{Q L T}{Q T O T A L} \\
& =\frac{440}{1420,4} \\
& =0,3096 \mathrm{smp} / \mathrm{jam}
\end{aligned}
$$

Rasio berbelok kanan :

$$
\begin{aligned}
P_{R T} & =\frac{Q R T}{Q T O T A L} \\
& =\frac{300}{1420,4} \\
& =0,2111 \mathrm{smp} / \mathrm{jam}
\end{aligned}
$$

Jadi, jumlah nilai rasio berbelok adalah :

$$
\begin{aligned}
P_{T} & =P_{L T}+P_{R T} \\
& =0,3096+0,2111 \\
& =0,5206 \mathrm{smp} / \mathrm{jam}
\end{aligned}
$$

3. Rasio jalan minor / (jalan utama + minor) total diperoleh : 


$$
\begin{aligned}
P_{M I} & =\frac{Q_{M I}}{Q_{T O T A L}} \\
= & \frac{573,6}{1420,4} \\
& =0,4038 \mathrm{smp} / \mathrm{jam}
\end{aligned}
$$

4. Rasio kendaraan tak bermotor diperoleh :

$$
\begin{aligned}
P_{U M}= & \frac{Q U M}{\text { QTOTAL }} \\
& =\frac{0}{1420,4} \\
& =0 \mathrm{smp} / \mathrm{jam}
\end{aligned}
$$

Menentukan lebar pendekat dan tipe simpang

a. Lebar pendekat jalan minor

Lebar pendekat Jalan minor $\mathrm{W}_{\mathrm{C}}=6,20 \mathrm{~m}$ dan lebar pendekat jalan minor $\mathrm{W}_{\mathrm{D}}=9,40$ $\mathrm{m}$, Lebar rata-rata pendekat $=3,9<5,5 \mathrm{~m}$. Dari tabel 2.3. didapat jumlah lajur total untuk kedua arah adalah 2.

b. Lebar pendekat jalan utama

Lebar pendekat jalan utama $\mathrm{W}_{\mathrm{A}}=7,00 \mathrm{~m}$, dan lebar pendekat jalan utama $\mathrm{W}_{\mathrm{B}}=$ $12,80 \mathrm{~m}$. Lebar rata-rata pendekat $=4,95<5,5 \mathrm{~m}$. Dari Tabel 2.3 didapat jumlah lajur total untuk kedua arah adalah 2.

c. Lebar pendekat rata-rata untuk jalan utama dan minor

$$
\begin{aligned}
W 1 & =(W A+W B+W C+W D) / 4 \\
& =(7,00+12,80+6,20+9,40) / 4 \\
& =8,85 \mathrm{~m}
\end{aligned}
$$

Diperoleh nilai $\mathrm{W}_{1}=8,85$

d. Tipe simpang untuk lengan simpang $=4$, jumlah lajur pada pendekat jalan utama dan jalan minor masing-masing $=2$, maka diperoleh tipe simpang (IT) $=422$.

Menentukan Kapasitas

a. Kapasitas dasar (Co)

Variabel masukan adalah tipe simpang $(\mathrm{IT})=422$, maka diperoleh kapasitas dasar $(\mathrm{Co})$ $=2900 \mathrm{smp} / \mathrm{jam}$.

b. Faktor penyesuaian kapasitas

- Lebar pendekat rata-rata $(\mathrm{Fw})$

Variabel masukan adalah lebar rata-rata semua pendekat $\mathrm{W}_{1}=8,85 \mathrm{~m}$ dan tipe simpang $(\mathrm{IT})=422$. Batas nilai yang diberikan untuk klasifikasi tipe simpang (IT) yaitu :

Untuk tipe simpang $422: \quad \mathrm{F}_{\mathrm{W}}=0,7+0,0886 \mathrm{~W}_{1}$

$$
=0,7+(0,0886 \times 8,85)
$$

Median jalan utama $\left(\mathrm{F}_{\mathrm{M}}\right)$

$$
=1,4664 \mathrm{~m}
$$

Nilai median untuk jalan utama yang tidak ada median adalah $\mathrm{F}_{\mathrm{M}}=1,0$.

- Ukuran kota $\left(\mathrm{F}_{\mathrm{CS}}\right)$

Berdasarkan variabel jumlah penduduk Kota Ende Tahun 2016 yaitu 88.389 jiwa < 0,1 juta jiwa didapat nilai $\mathrm{F}_{\mathrm{CS}}=0,82$.

- Hambatan samping ( $\left.\mathrm{F}_{\mathrm{RSU}}\right)$

Hambatan samping yang dipakai Berdasarkan data survei, variabel kelas tipe lingkungan simpang adalah komersial, kelas hambatan samping $\left(\mathrm{S}_{\mathrm{F}}\right)$ adalah tinggi, dan rasio kendaraan tak bermotor $\left(\mathrm{U}_{\mathrm{M}} / \mathrm{M}_{\mathrm{V}}\right)=0,00$. Didapat nilai $\mathrm{F}_{\mathrm{RSU}}=0,93$.

Belok kiri $\left(\mathrm{F}_{\mathrm{LT}}\right)$

Variabel masukan adalah rasio belok kiri $\mathrm{P}_{\mathrm{LT}}=0,3096$ Batas nilai yang diberikan digunakan rumus :

$$
\begin{aligned}
F_{L T} & =0,84+1,61 \mathrm{P}_{\mathrm{LT}} \\
& =0,84+(1,61 \times 0,3096) \\
& =1,3384
\end{aligned}
$$

TEKNOSIAR Volume 14, No.01, April 2020

p-ISSN 1907-5197 (versi cetak) e-ISSN 2721-2270 (versi online) 
- Belok kanan $\left(F_{R T}\right)$

Variabel masukan adalah rasio belok kanan $\mathrm{P}_{\mathrm{RT}}=0,211$. Batas nilai yang diberikan untuk simpang 4 lengan, $\mathrm{F}_{\mathrm{RT}}=1,0$.

- Rasio minor / total ( $\left.F_{\text {MI }}\right)$

Variabel masukan adalah rasio arus jalan minor $\mathrm{P}_{\mathrm{MI}}=0,4038$

dan tipe simpang $\mathrm{IT}=422$. Batas nilai yang diberikan untuk $\mathrm{F}_{\mathrm{MI}}$ dengan menggunakan rumus

$$
\begin{aligned}
\mathrm{F}_{\mathrm{MI}} & =1,19 \times \mathrm{P}_{\mathrm{MI}}^{2}-1,19 \times \mathrm{P}_{\mathrm{MI}}+1,19 \\
& =1,19 \times 0,4038^{2}-1,19 \times 0,4038+1,19 \\
& =0,9035
\end{aligned}
$$

-Kapasitas (C) diperoleh :

$$
\begin{aligned}
\mathrm{C} & =\mathrm{C}_{O} \times \mathrm{F}_{W} \times \mathrm{F}_{M} \times \mathrm{F}_{C S} \times \mathrm{F}_{R S U} \times \mathrm{F}_{L T} \times \mathrm{F}_{R T} \times \mathrm{F}_{M I} \\
& =2900 \times 1,4664 \times 1 \times 0,82 \times 0,93 \times 1,3384 \times 1,0 \times 0,9035 \\
& =1881,05 \mathrm{smp} / \mathrm{jam}
\end{aligned}
$$

\section{Perilaku Lalu lintas}

a. Arus Lalu lintas $(\mathrm{Q}) \geq$

Arus lalu lintas total $\left(\mathrm{Q}_{\mathrm{MV}}\right)=1420,4 \mathrm{smp} / \mathrm{jam}$

Derajat Kejenuhan (DS)

Untuk $\mathrm{Q}_{\mathrm{Mv}}=1420,4 \mathrm{smp} / \mathrm{jam}$ dan $\mathrm{C}=1881,05 \mathrm{smp} / \mathrm{jam}$ didapat :

$$
\begin{aligned}
D S & =\frac{Q_{\text {TOTAL }}}{C} \\
& =1420,4 / 1881,05 \\
& =0,7551
\end{aligned}
$$

Berdasarkan ketentuan derajat kejenuhan jika nilai DS $>0,75$ maka dapat dikatakan tingkat kelayakan persimpangan Patung Pahlawan Mariloga sudah mencapai kapasitas yang ditandai standar nilai DS yang sudah melampau 0,75

b. Tundaan Lalu lintas

1) Tundaan lalu lintas simpang $\left(\mathrm{DT}_{\mathrm{I}}\right)$

Variabel masukan adalah derajat kejenuhan $\mathrm{DS}=0,75 . \mathrm{DT}_{\mathrm{I}}$ ditentukan dari kurva empiris antara $\mathrm{DT}_{\mathrm{I}}$ dan DS ditentukan dengan rumus, untuk $\mathrm{DS}>0,6$ :

$$
\begin{aligned}
D T_{I} & =\frac{1,0504}{(0,2742-0,2042 \times D S)}-(1-D S) \times 2 \\
& =\frac{1,0504}{(0,2742-0,2042 \times 0,75)}-(1-0,75) \times 2 \\
& =8,2631
\end{aligned}
$$

Diperoleh nilai $\mathrm{DT}_{\mathrm{I}}=8,2631$ dari perhitungan dengan rumus $\mathrm{DS}>0,6$.

2) Tundaan lalu lintas jalan utama ( $\left.\mathrm{DT}_{\mathrm{MA}}\right)$

Variabel masukan adalah derajat kejenuhan $\mathrm{DS}=0,75 . \mathrm{DT}_{\mathrm{MA}}$ ditentukan dengan dengan rumus 2.13 untuk DS $>0,6$ :

$$
\begin{aligned}
D T_{M A} & =\frac{1,0504}{(0,346-0,24 \times D S)}-(1-D S) \times 1,8 \\
& =\frac{1,0504}{(0,346-0,24 \times 0,75)}-(1-0,75) \times 1,8 \\
& =6,1139
\end{aligned}
$$

Diperoleh nilai $\mathrm{DT}_{\mathrm{MA}}=6,1139$ dari perhitungan dengan rumus $\mathrm{DS}>0,6$.

3) Tundaan lalu lintas jalan minor ( $\left.\mathrm{DT}_{\mathrm{MI}}\right)$

Variabel masukan adalah arus lalu lintas total $\mathrm{Q}_{\mathrm{MV}}=1420,4 \mathrm{smp} / \mathrm{jam}$, Tundaan lalu lintas simpang $\mathrm{DT}_{\mathrm{I}}=8,2631$, arus lalu lintas jalan utama $\mathrm{Q}_{\mathrm{MA}}=847 \mathrm{smp} / \mathrm{jam}$, Tundaan lalu lintas jalan utama $\mathrm{DT}_{\mathrm{MA}}=6,1139 \mathrm{smp} / \mathrm{jam}$, arus lalu lintas jalan minor $\mathrm{Q}_{\mathrm{MI}}=573,6 \mathrm{smp} / \mathrm{jam}$. Digunakan rumus :

$$
D T_{M I}=\frac{\left(Q_{T O T A L} \times D T_{I}\right)-\left(Q_{M A} \times D T_{M A}\right)}{Q_{M I}}
$$

TEKNOSIAR Volume 14, No.01, April 2020 


$$
\begin{aligned}
& =\frac{(1420,4 \times 8,2631)-(847 \times 6,1139)}{573,6} \\
& =11,4359
\end{aligned}
$$

Diperoleh nilai $\mathrm{DT}_{\mathrm{MI}}=11,4359$.

4) Tundaan geometrik simpang (DG)

Untuk mendapatkan nilai $\mathrm{DG}$, dimana rasio belok total $\left(\mathrm{P}_{\mathrm{T}}\right)=0,4038$, derajat kejenuhan $(\mathrm{DS})=0,75$. Untuk $\mathrm{DS}<1,0$ digunakan rumus :

$$
\begin{aligned}
\mathrm{DG} & =(1-\mathrm{DS}) \times(\mathrm{PT} \times 6+(1-\mathrm{PT}) \times 3)+\mathrm{DS} \times 4 \\
& =(1-0,75) \times(0,4038 \times 6+(1-0,4038) \times 3)+0,75 \times 4 \\
& =5,2235
\end{aligned}
$$

Diperoleh nilai $\mathrm{DG}=5,2235$ dari perhitungan dengan rumus $\mathrm{DS}<1,0$.

5) Tundaan simpang (D)

Dengan nilai $\mathrm{DG}=5,2235$ dan nilai $\mathrm{DT}_{\mathrm{I}}=8,2631$, maka diperoleh nilai $\mathrm{D}$ sbb :

$$
\begin{aligned}
\mathrm{D} & =\mathrm{DG}+\mathrm{DT}_{\mathrm{I}} \\
& =5,2235+8,2631 \\
& =13,4866(\mathrm{det} / \mathrm{smp})
\end{aligned}
$$

Didapat nilai $\mathrm{D}=13,4866 \mathrm{det} / \mathrm{smp}$.

6) Peluang antrian

Rentang nilai peluang antrian dapat dihitung menggunakan rumus :

Batas bawah :

$$
\begin{aligned}
\mathrm{QP} \%= & 9,02 \times \mathrm{DS}+20,66 \times \mathrm{DS}^{2}+10,49 \times \mathrm{DS}^{3} \\
& =9,02 \times 0,75+20,66 \times 0,31^{2}+10,49 \times 0,31^{3} \\
& =22,81 \%
\end{aligned}
$$

Batas atas :

$$
\begin{aligned}
\mathrm{QP} \% & =47,71 \times \mathrm{DS}-24,68 \times \mathrm{DS}^{2}+56,47 \times \mathrm{DS}^{3} \\
& =47,71 \times 0,75-24,68 \times 0,75^{2}+56,47 \times 0,75^{3} \\
& =45,72 \%
\end{aligned}
$$

Dengan rumus diatas didapat rentang nilai peluang antrian $\mathrm{QP}^{\mathrm{c}} \mathrm{o}=23 \%-46 \%$.

\section{Alternatif Pengendalian}

Nilai derajat kejenuhan (DS) sebesar 0,7551. Sudah lebih sedikit melampaui batas nilai yang disarankan MKJI, 1997 yaitu nilai 0,75. Sehingga dilakukan scenario berupa menghilangkan volume arus jalan minor yang melawan arah dan mengubah hambatan samping dari tinggi menjadi rendah atau memindahkan para pedagang yang berjualan di sekitar lokasi simpang. Hasil kinerja simpang yang diperoleh dapat dilihat pada Tabel 1.2 sebagai berikut :

Tabel 1.2 Rekapitulasi hasil perhitungan Kinerja Simpang

\begin{tabular}{|c|c|c|c|c|c|c|}
\hline \multirow{2}{*}{ Skenario } & $\begin{array}{c}\text { Kapasitas } \\
\text { Dasar } \\
(\mathbf{C o})\end{array}$ & $\begin{array}{c}\text { Kapa } \\
\text { sitas } \\
(\mathbf{C})\end{array}$ & $\begin{array}{c}\text { Arus Lalu } \\
\text { Lintas } \\
(\mathbf{Q})\end{array}$ & $\begin{array}{c}\text { Derajat } \\
\text { Kejenuhan } \\
(\mathbf{D S})\end{array}$ & Tundaan & $\begin{array}{c}\text { Peluang } \\
\text { Antrian } \\
(\mathbf{Q P})\end{array}$ \\
\cline { 2 - 7 } & smp/jam & smp/jam & smp/jam & & det/smp & $\%$ \\
\hline 1 & 2900 & 1881,05 & 1420,4 & 0,7551 & 13,4866 & $23-46$ \\
\hline 2 & 2900 & 4300,87 & 1346,1 & 0,3130 & 8,1031 & $5-14$ \\
\hline
\end{tabular}

Sumber : Hasil analisa, 2018

Hasil analisa kinerja simpang pada skenario 2 yakni tindakan pelarangan pergerakan yang berlawanan arah dan pemindahan para pedagang di sekitar lokasi simpang diperoleh volume lalu $\operatorname{lintas}(\mathrm{Q})=1346,1 \mathrm{smp} / \mathrm{jam}$, kapasitas $(\mathrm{C})$ sebesar $=4300,87 \mathrm{smp} / \mathrm{jam}$, tundaan $(\mathrm{D})=8,1031$ det/smp dan menghasilkan derajat kejenuhan (DS) sebesar $=0,3130$. Dari nilai derajat kejenuhan (DS) yang didapat memenuhi nilai yang disarankan MKJI 1997 yaitu DS $<0,75$. Hasil ini menunjukan bahwa pilihan skenario menghilangkan arus yang melawanan arah dan mengubah 
hambatan samping dari tinggi menjadi rendah sudah mencapai sasaran yang diinginkan sesuai ketentuan MKJI, 1997.

\section{KESIMPULAN}

Hasil analisa kinerja simpang Marilonga pada kondisi eksisting ditunjukan melalui parameter kinerja seperti arus lalu lintas $(\mathrm{Q})=1420,4 \mathrm{smp} / \mathrm{jam}$, nilai kapasitas $(\mathrm{C})$ sebesar $=1881,05$ smp/jam, tundaan (D) =13,4866 det/smp dan menghasilkan derajat kejenuhan (DS) sebesar 0,7551. Kondisi ini menandankan Kinerja simpang sudah mendekati kapasitas dengan tingkat pelayanan dalam kategori $\mathrm{C}$.

selanjutnya melalui skenario pengendalian melalui upaya menghilangkan volume arus jalan minor, yaitu dari arah jalan Ndona lurus menuju jalan Sam Ratulangi, karena melawan arah dan mengubah hambatan samping dari tinggi menjadi rendah (melalui pemindahan para pedagang yang berjualan di sekitar lokasi simpang), maka nilai derajat kejenuhan diperoleh sebesar(DS) $=0,31$ berada pada kategori baik. Tentunya upaya yang dilakukan pada skenario tersebut perlu diaplikasikan dalam bentuk pememasang rambu-rambu lalu lintas pada daerah persimpangan tersebut untuk mencegah adanya pergerakan lurus yang berasal dari arah jalan Ndona, serta rambu dilarang berjualan bagi para penjual disekitar lokasi simpang.

\section{DAFTAR PUSTAKA}

Direktorat Jenderal Bina Marga, Departemen Pekerjaan Umum RI. 1997. Manual Kapasitas Jalan Indonesia. Jakarta.

Direktorat Bina Sistem Lalu Lintas dan Angkutan Kota, Direktorat Jenderal Perhubungan Darat. 1999. Pedoman Pengumpulan Data Lalu Lintas Jalan.

Effendi, Muchson. 2014. Evaluasi Kinerja Simpang Tak Bersinyal Gondang Kota Surakarta. Jurusan Teknik Sipil Universitas Sebelas Maret Surakarta. Surakarta.

Khisty, C. Jotin dan B. Kent Lall. 2005. Dasar-dasar Rekayasa Transportasi. Jakarta: Erlangga.

Miro, Fidel. 2012. Pengantar Sistem Transportasi. Jakarta: Erlangga.

Morlok, Edward K. 1991. Pengantar Teknik dan Perencanaan Transportasi. Jakarta: Erlangga.

Rorong, Novriyadi. 2015. Analisa Kinerja Simpang Tak Bersinyal di Ruas Jalan S.Parman dan Jalan D.I.Panjaitan. Jurusan Teknik Sipil Universitas Sam Ratulangi. Manado.

Suleman, Farid. 2016. Analisis Kinerja Simpang Tak Bersinyal (Studi Kasus : Simpang 3 lengan tak bersinyal Jalan Wates Km.17 - Jalan Pengasih). Jurusan Teknik Sipil Universitas Muhammadiyah. Yogyakarta.

Tamin, Ofyar Z. 1997. Perencanaan dan Pemodelan Transportasi. Bandung: ITB.

Well G.R. 1993. Rekayasa Lalu Lintas. Jakarta: Bhratara. 